\title{
Racial/Ethnic Group Differences in Bipolar Symptomatology in a Community Sample of Persons With Bipolar I Disorder
}

\author{
Brian E. Perron, PhD, *广 Lauren E. Fries, MSW, * Amy M. Kilbourne, PhD, †f Michael G. Vaughn, PhD, $\$$ \\ and Mark S. Bauer, MDq\|
}

\begin{abstract}
To better understand the problems associated with diagnosis of bipolar disorder, especially problems related to race and ethnicity, this study compared whites, African Americans, and Latinos with bipolar I disorder in the presentation of manic symptoms, depressive episodes, functional impairments (Short Form-12), and self-reports of schizophrenia diagnosis. Data for this study were derived from the 2001 National Epidemiologic Survey on Alcohol and Related Conditions, which are nationally representative of United States households. African Americans and Latinos expressed similar rates in presentation of 14 out of 16 manic symptoms compared with whites, with the exception of grandiosity/self-esteem, in which they were more likely to exhibit this symptom compared with whites. Higher rates of depressive episodes were observed among whites, and these episodes occurred significantly earlier compared with African Americans and Latinos. Latinos had slightly higher vitality scores on the SF-12 measures after adjusting for sociodemographic and clinical factors, but no other differences across the groups were observed. Overall, these data show that the expression and functional impairments of bipolar I disorder is very similar across racial ethnic groups using this community-based sample. This is the first community-based study making such comparisons, with results suggesting that provider biases are more likely to explain problems in misdiagnosis than fundamental differences in the presentation of bipolar disorder across racial/ ethnic groups.
\end{abstract}

Key Words: Bipolar disorder, ethnic differences, ethnic disparities

(J Nerv Ment Dis 2010;198: 16-21)

$S_{\mathrm{p}}^{\mathrm{c}}$ erious mental illness (schizophrenia, bipolar disorder) is a major public health problem, resulting in adverse functional, social and economic outcomes and premature mortality. Bipolar disorder in particular can affect up to $5.5 \%$ of the US population (Judd and Akiskal, 2003), and research suggests that this illness is diagnosed at similar rates across racial/ethnic groups when structured clinical assessments are used (Minsky et al., 2003). Misdiagnosis of bipolar disorder has been observed, and it can take up to 10 years on average

*School of Social Work, University of Michigan, Ann Arbor, MI; †VA Ann Arbor Healthcare System, Serious Mental Illness Treatment Research and Evaluation Center, Ann Arbor, MI; $\$$ Department of Psychiatry, University of Michigan, Ann Arbor, MI; §School of Social Work, Division of Epidemiology, School of Public Health, Department of Policy Studies, Saint Louis University, St. Louis, MO; ๆHarvard South Shore Psychiatry Residency Training Program, Harvard Medical School, Boston, MA; and \|VA Boston Healthcare System, Boston, MA.

Supported by the Department of Veterans Affairs, Veterans Health Administration, Health Services Research and Development Service and Office of Mental Health Services, and by the Curtis Center of the University of Michigan School of Social Work.

The views expressed in this article are those of the authors and do not necessarily represent the views of the Department of Veterans Affairs or the Curtis Center.

Send reprint requests to Brian E. Perron, PhD, School of Social Work, University of Michigan, 1080 S. University Ave, Ann Arbor, MI 48103. E-mail: beperron@umich.edu.

Copyright (C) 2010 by Lippincott Williams \& Wilkins

ISSN: 0022-3018/10/19801-0016

DOI: $10.1097 / \mathrm{NMD} .0 \mathrm{~b} 013 \mathrm{e} 3181 \mathrm{c} 818 \mathrm{c} 5$ for a person to be correctly diagnosed with this condition (Hirschfeld et al., 2003), increasing risk for inappropriate treatment and adverse outcomes (e.g., antidepressant monotherapy and manic episode, rapid cycling). Hence, accurate diagnosis of illness is paramount towards appropriate treatment and recovery for persons with bipolar disorder.

However, evidence suggests that in routine care African Americans are underdiagnosed for bipolar disorder and over-diagnosed for schizophrenia (Chen et al., 1998; Jones and Gray, 1986; Kilbourne et al., 2004; Strakowski et al., 2003; Zhang and Snowden, 1999). These differences persist even though rates of both conditions are similar across racial/ethnic groups when clinician assessments are used. Such diagnostic errors have been observed in routine, community-based mental health inpatient and outpatient settings (Strakowski et al., 2003), where structured clinical assessments are not regularly used. Even with improvements in diagnostic criteria of the DSM-IV, racial differences in diagnosis continue to exist in routine care (Strakowski et al., 1995).

Racial/ethnic differences in bipolar diagnosis may be due to bias in clinical misinterpretation of symptoms. Research has demonstrated systematic racial and ethnic variations in the expression of psychopathology. Most notably, African Americans with bipolar disorder tend to present with more severe psychotic symptoms, particularly auditory hallucinations, persecutory delusions, and delusions of inference, compared with whites (Kennedy et al., 2004; Strakowski et al., 1996; van Os et al., 1996). Combined with increased levels of functional impairments (Lawson et al., 1994), these racial and ethnic differences in symptom presentation may be a key source for overdiagnosis of a schizophrenia spectrum condition. Other challenges to the diagnostic process relate to differences in temporal ordering of manic and depressive episodes across racial and ethnic groups. For example, Kennedy et al. (2004) found that African Americans were more likely to have an earlier onset of mania compared with whites, and whites were more likely to present with a depressive episode before mania (Kennedy et al., 2004). Latinos were more likely to present with depressive symptoms than whites (Minsky et al., 2003); evidence regarding whether Latinos are more or less likely to present psychotic symptoms has been mixed (Vega et al., 2007), yet nonetheless language and cultural barriers have been associated with differential diagnoses in this group. Kirov and Murray (1999) found that whites were more likely to present with higher levels of suicidal ideation than other groups, but no consistent evidence has been observed in the presentation of depressive symptoms (Patel et al., 2006; Raskin et al., 1975).

At present, few studies have examined the extent to which symptoms differ between racial groups or examined whether racial/ ethnic bias in diagnosis may be explained by differential presentation of bipolar disorder symptoms. These studies were also limited by small sample sizes or selection biases (e.g., specialty treatment settings). Knowing how bipolar syndrome manifests differently across groups can guide assessment strategies to minimize misdiagnosis. Toward this end, this study systematically examined rates of DSM-IV manic symptoms among whites, Latinos, and African Americans with bipolar I disorder using a large psychiatric epide- 
miological survey. To help understand the extent to which bipolar I disorder varies across whites and African Americans, this study also compared age of onset of mania, rates and temporal ordering of depressive episodes, functional impairments, and history of a schizophrenia diagnosis. To our knowledge, this is the first study making such comparisons using a nationally representative community-based sample.

\section{METHODS}

This study reports findings based on data from the 2001-2002 National Epidemiologic Survey on Alcohol and Related Conditions (NESARC). NESARC includes a representative sample of 43,093 US adults (Grant et al., 2004). The survey gathered information on substance use and comorbid conditions from individuals living in households and group settings.

NESARC used a multistage sampling design and had an overall response rate of $81 \%$. Data were weighted at the individual and household levels and adjusted for oversampling, nonresponse, and to be representative of the US population as assessed during the 2000 census.

US Census Bureau workers administered the Alcohol Use Disorders and Associated Disabilities Interview Schedule (AUDADIS-IV). AUDADIS-IV is a structured interview designed for administration by trained lay interviewers. AUDADIS-IV assesses DSM-IV substance use and psychiatric disorders with good reliability (Grant et al., 2003). The NESARC survey, sampling protocol, related publications, and codebook are available at http://www.nesarc.niaaa.nih.gov/.

\section{Measurement}

\section{Race and Ethnicity}

Survey respondents were asked to self-identify their racial/ ethnic group membership. Subjects could not self-identify as having more than one group membership.

\section{Bipolar Disorder}

Survey respondents were identified as having lifetime bipolar I (BP-I) disorder if they ever met criteria for a DSM-IV manic episode, using the AUDADIS-IV. The reliability of the AUDADIS-IV diagnosis of bipolar diagnosis is acceptable ([kap$p a]=0.59$ ) (Grant et al., 2005). This estimate of reliability is slightly lower than typically found for the Structured Clinical Interview for DSM Disorders (e.g., 0.76-0.97; Perala et al., 2007). The AUDADIS-IV contains 15 different manic symptoms, which are used to construct the DSM-IV criteria for a manic episode. Comparisons were made across all 15 symptoms in addition to the 7 constructed symptoms that are concordant with the DSM-IV. Survey respondents also indicated their age of their first manic episode.

\section{Depressive Episode}

Survey respondents were coded as having a lifetime depressive episode if they met DSM-IV criteria as measured by the AUDADIS-IV. Survey respondents also indicated their age of their first depressive episode.

\section{Schizophrenia Diagnosis}

Survey respondents were asked whether they have ever been informed by a doctor or other health professional that they had schizophrenia or another psychotic illness.

\section{Functioning}

Functioning was measured using scales from the 12-item Short-Form Health Survey, version 2 (SF-12v2) (Ware et al., 1996). These scales measure physical, mental, and psychosocial domains of functioning. Each score is presented as a continuous measure, ranging from 0 to 100 points. Lower scores indicate a greater level of functioning. A mean value of 50 represents the expected value in the general population. Scales from this instrument serve as indicators of quality of life in a substantial body of mental health services research (Trivedi et al., 2004a; Trivedi et al., 2004b; Vojta et al., 2001) and have demonstrated good psychometric properties (Ware et al., 1996).

\section{Covariates}

Socio-demographic variables were also ascertained, including age (in years), gender, living area (i.e., urban or rural), education, lifetime history of an alcohol use or drug use disorder (excluding nicotine), lifetime history of an anxiety disorder (i.e., social phobia, panic disorder with or without agoraphobia, and generalized anxiety disorder), and lifetime personality disorders (i.e., antisocial, avoidant, dependent, obsessive-compulsive, paranoid, schizoid, and histrionic).

\section{Analytic Plan}

Univariate statistics were used to describe the study sample. Two sets of analyses were conducted to identify differences in mania across the racial/ethnic groups. The first set involved a complete examination of 16 individual symptoms of mania included in the AUDADIS-IV that are used to measure a DSM-IV manic episode. The second set of analyses combined the indicators to reflect the actual DSM-IV criteria. Group differences were tested using chi square analyses. When significant differences were observed, pairwise comparisons were conducted to identify specific group differences. Symptoms that exhibited significant differences at the bivariate level were then examined using multivariate logistic regression analyses. These analyses adjusted for sociodemographic (i.e., sex, age, education, urbanicity) and clinical variables (i.e., lifetime history of major depressive episode, alcohol use disorder, drug use disorder, anxiety disorder, and personality disorder).

Differences in rates of being informed of having a schizophrenia diagnosis and history of a depressive episode were also tested using the same analytic strategy for examining differences in symptoms. Differences in mean ages of onset of manic and depressive episodes, in addition to scores on the SF-12 measures, were compared used F-tests. Pairwise comparisons and multivariate linear regression analyses were also conducted when group differences were identified. Multivariate linear regression analyses controlled for sociodemographic (i.e., sex, age, education, urbanicity) and clinical variables (i.e., lifetime history of major depressive episode, alcohol use disorder, drug use disorder, anxiety disorder, and personality disorder).

All analyses were conducted using SUDAAN v. 9.0. SUDAAN implements a Taylor series linearization to adjust standard errors of estimates for complex survey sampling design effects involving clustered data.

\section{RESULTS}

\section{Sample Description}

Approximately $3.6 \%$ of persons surveyed in the NESARC met lifetime criteria for bipolar I disorder. Rates were comparable across racial/ethnic groups (African Americans $=3.8 \%$, whites $=3.6 \%$, and Latinos $=3.4 \%$ ), and no statistically significant differences were observed based on a chi square test $\left(\chi^{2}[2]=1.11, p=0.576\right)$.

\section{Socio-Demographics}

Among persons with bipolar I disorder, slightly more than half were female $(53.8 \%)$, about $49.5 \%$ had more than a high school education, and almost one-third (31.1\%) lived in urban 
TABLE 1. Sociodemographics and Clinical Characteristics of Adults With Manic Disorder by Racial/Ethnic Groups

\begin{tabular}{|c|c|c|c|c|c|}
\hline Variable & $\begin{array}{l}\text { Overall } \\
\%(S E)\end{array}$ & $\begin{array}{l}\text { White } \\
\%(S E)\end{array}$ & $\begin{array}{c}\text { African-American } \\
\%(S E)\end{array}$ & $\begin{array}{l}\text { Latino } \\
\%(S E)\end{array}$ & $p$ \\
\hline \multicolumn{6}{|l|}{ Sex } \\
\hline Male & $46.23(1.66)$ & $46.71(2.00)$ & $38.19(3.06)$ & $51.85(4.12)$ & 0.018 \\
\hline Female & $53.77(1.66)$ & $53.29(2.00)$ & $61.81(3.06)$ & $48.15(4.12)$ & \\
\hline \multicolumn{6}{|l|}{ Education } \\
\hline Less than high school & $19.64(1.27)$ & $16.16(1.52)$ & $22.26(2.91)$ & $39.91(4.05)$ & 0.001 \\
\hline High school & $30.82(1.50)$ & $31.18(1.80)$ & $35.21(3.21)$ & $23.68(3.46)$ & \\
\hline More than high school & $49.54(1.75)$ & $52.67(2.30)$ & $42.53(3.66)$ & $36.41(4.47)$ & \\
\hline \multicolumn{6}{|l|}{ Living area } \\
\hline Urban & $31.11(2.24)$ & $24.46(2.19)$ & $57.64(4.39)$ & $46.30(5.98)$ & 0.000 \\
\hline Rural & $68.89(2.24)$ & $75.54(2.19)$ & $42.36(4.39)$ & $53.70(5.98)$ & \\
\hline \multicolumn{6}{|l|}{ Age } \\
\hline $18-34$ & $44.2(1.5)$ & $42.2(1.7)$ & $45.2(3.3)$ & $55.5(3.9)$ & 0.031 \\
\hline $35-54$ & $41.3(1.6)$ & $43.4(1.9)$ & $40.0(3.2)$ & $28.3(3.4)$ & \\
\hline $55+$ & $14.6(1.1)$ & $14.4(1.3)$ & $14.8(2.4)$ & $16.2(3.3)$ & \\
\hline Lifetime personality disorder & $60.17(1.67)$ & $60.50(2.05)$ & $58.70(3.14)$ & $59.64(3.99)$ & 0.897 \\
\hline Lifetime alcohol use disorder & $57.89(1.71)$ & $60.09(1.92)$ & $50.11(4.41)$ & $51.77(4.40)$ & 0.047 \\
\hline Lifetime anxiety disorder & $56.67(1.59)$ & $59.33(1.87)$ & $52.98(3.64)$ & $43.01(3.92)$ & 0.004 \\
\hline Lifetime drug use disorder & $37.46(1.68)$ & $38.75(1.92)$ & $36.96(4.27)$ & $29.39(3.81)$ & 0.168 \\
\hline
\end{tabular}

areas (Table 1). Persons 55 years and older represented the smallest age group $(14.6 \%)$. Racial/ethnic differences were observed across these sociodemographic variables. African Americans with bipolar disorder were more likely to be female and live in urban areas. Latinos had the lowest levels of education.

\section{Clinical Characteristics}

Approximately $57.9 \%$ of persons with bipolar I disorder met criteria for a lifetime alcohol use disorder and 37.5\% met criteria for a lifetime drug use disorder. Prevalence of a lifetime anxiety and lifetime personality disorder were also high $(56.7 \%$ and $60.2 \%$, respectively). Whites exhibited the highest rates of alcohol use disorders and anxiety disorders, but no significant differences were observed for personality. Whites exhibited slightly higher rates of alcohol use disorders than African Americans and Latinos, but no racial/ethnic differences were observed for drug use disorders.

\section{Differences in Manic Symptoms}

The first set of analyses examined a total of 16 different symptoms that are used in the AUDADIS-IV (Table 2). The most common symptoms included difficulty concentrating (84.2\%), feeling restless $(81.8 \%)$, and racing thoughts $(80.7 \%)$. The least common included inflated self-esteem $(28.7 \%)$, increased sexual activity $(24.8 \%)$, and legal troubles $(12.6 \%)$.

Chi square tests revealed 2 of the 16 symptoms that exhibited significant differences across the racial/ethnic groups, which included feeling excessively restless $\left(\chi^{2}[2]=12.69, p<0.003\right)$ and inflated self-esteem/grandiosity $\left(\chi^{2}[2]=15.7, p<0.001\right)$. The prevalence of the latter symptom among African Americans and Latinos was approximately 50\% higher compared with whites $(39.9 \%, 38.8 \%$, and $25.3 \%$, respectively). Multivariate logistic regression, which controlled for sociodemographic and other clinical variables, showed that African Americans were approximately 2.40 times more likely $(95 \% \mathrm{CI}=1.88-3.05)$ and Latinos were approximately 1.54 times more likely $(95 \% \mathrm{CI}=1.13-2.10)$ to report this symptom compared with whites.
The second set of analyses combined the individual symptoms to reflect the DSM-IV diagnostic criteria for manic episode (Table 3). Only one diagnostic criterion among the 7 symptoms exhibited statistically significant differences - that is, inflated selfesteem/grandiosity. This diagnostic criterion was based on only one indicator, so the significant differences reported in the first set of analyses are the same. The other symptom that was significant in the first set of analysis - that is, excessive restlessness or fidgeting — did not result in significant differences when combined with other indicators (i.e., increased activity at work, home, or while performing activities of interest, as well as physical restlessness that was uncomfortable) to reflect the DSM-IV criterion "Increased goal directed activity or psychomotor agitation."

\section{Mania Onset}

The average age of first manic episode among African Americans and whites with bipolar I disorder was 25.5 years $(95 \% \mathrm{CI}=$ 24.6-26.3). No significant differences in age of onset was observed across the racial/ethnic groups in bivariate analyses $(F[2]=1.28$, $p=0.285)$.

\section{Depressive Episodes}

The overall rate of lifetime depressive episodes among the study sample was $71.2 \%(95 \% \mathrm{CI}=68.1 \%-74.2 \%)$, with significant differences observed across the groups $\left(\chi^{2}[2]=19.93, p<0.001\right)$ Whites had the highest rates of depressive episodes $(75.0 \%)$, followed by African Americans (62.4\%) and Latinos (55.6\%). The average age of first depressive episode was $24.3(95 \% \mathrm{CI}=$ 23.4-25.1). An $F$-test revealed significant racial/ethnic differences $(F[2]=1562.16, p<0.001)$.

\section{Functional Impairments}

$F$-tests were used to test differences in functional impairments among whites and African Americans. Of the 10 SF-12 measures examined, vitality was the only measure that exhibited significant racial/ethnic differences $(F[2]=9.83, p<0.001)$. 
TABLE 2. Prevalence of Manic Symptoms Among Racial/Ethnic Groups With Lifetime Bipolar I Disorder

\begin{tabular}{|c|c|c|c|c|c|}
\hline Symptom & $\begin{array}{l}\text { Overall } \\
\%(S E)\end{array}$ & $\begin{array}{l}\text { White } \\
\%(S E)\end{array}$ & $\begin{array}{l}\text { African American } \\
\quad \%(S E)\end{array}$ & $\begin{array}{l}\text { Latino } \\
\%(S E)\end{array}$ & $p$ \\
\hline Had trouble concentrating because little things got you easily off track & $84.2(1.4)$ & 84.5 (1.6) & 82.4 (4.0) & $83.2(3.5)$ & 0.853 \\
\hline Felt so restless you fidgeted, paced, or could not sit still & $81.8(1.4)$ & $84.2(1.6)$ & $67.0(4.3)^{\mathrm{a}}$ & $75.6(3.8)^{\mathrm{a}}$ & 0.003 \\
\hline Thoughts raced so fast that you could not keep track of them & $80.7(1.6)$ & $81.8(1.8)$ & $78.2(3.7)$ & $80.2(3.8)$ & 0.747 \\
\hline Thoughts raced so fast that it was hard to follow your own thoughts & $73.1(1.8)$ & $73.4(2.0)$ & $72.3(4.0)$ & $71.6(3.6)$ & 0.889 \\
\hline $\begin{array}{l}\text { Was uncomfortable because of feeling extremely excited/elated/irritable/ } \\
\text { easily annoyed }\end{array}$ & $64.9(2.0)$ & $64.8(2.4)$ & $63.6(4.2)$ & $67.3(3.8)$ & 0.757 \\
\hline Had trouble getting things done & $63.6(2.1)$ & $63.2(2.3)$ & $62.3(5.0)$ & $69.6(4.3)$ & 0.329 \\
\hline Needed much less sleep than usual & $63.1(1.6)$ & $62.4(1.9)$ & $65.7(4.1)$ & $66.4(3.9)$ & 0.538 \\
\hline $\begin{array}{l}\text { Became more active than usual at work, home, or while pursuing other } \\
\text { interests }\end{array}$ & $63.1(1.8)$ & $62.5(2.2)$ & $69.6(4.3)$ & $59.9(4.5)$ & 0.234 \\
\hline More talkative than usual & $62.1(1.9)$ & $62.2(2.3)$ & $66.1(4.0)$ & $56.4(4.8)$ & 0.312 \\
\hline Difficulty getting along with others/arguing with friends & $58.7(1.7)$ & $59.8(2.1)$ & $53.1(4.4)$ & $55.8(4.1)$ & 0.356 \\
\hline Became so physically restless that it made you uncomfortable & $58.2(2.1)$ & $58.9(2.4)$ & $52.9(5.8)$ & $58.6(4.5)$ & 0.605 \\
\hline $\begin{array}{l}\text { Had serious problems with things supposed to do-work, schoolwork, } \\
\text { caring for home/family }\end{array}$ & $51.4(1.9)$ & $51.5(2.3)$ & $49.0(4.5)$ & $53.7(3.7)$ & 0.742 \\
\hline Talked so fast people had trouble understanding & $46.5(2.1)$ & $46.6(2.5)$ & $48.2(5.2)$ & $42.9(4.4)$ & 0.712 \\
\hline Inflated self-esteem or grandiosity & $28.7(1.6)$ & $25.3(1.7)^{\mathrm{a}, \mathrm{b}}$ & $39.9(3.3)^{\mathrm{a}}$ & $38.8(4.3)^{\mathrm{b}}$ & $<0.001$ \\
\hline Became more sexually active & $24.8(1.7)$ & $26.3(2.1)$ & $24.7(3.7)$ & $20.5(3.3)$ & 0.530 \\
\hline Had legal trouble—getting arrested & $12.6(1.3)$ & $12.0(1.5)$ & $17.2(3.6)$ & $12.6(2.9)$ & 0.432 \\
\hline
\end{tabular}

${ }^{\mathrm{a}, \mathrm{b}}$ Represent group differences based on pair-wise comparisons $(p<0.05)$.

TABLE 3. Prevalence of DSM-IV -IV Symptoms for Manic Episode by Racial/Ethnic Groups

\begin{tabular}{|c|c|c|c|c|c|}
\hline Manic Symptoms & $\begin{array}{l}\text { Total } \\
\%(S E)\end{array}$ & $\begin{array}{l}\text { White } \\
\%(S E)\end{array}$ & $\begin{array}{c}\text { African American } \\
\%(S E)\end{array}$ & $\begin{array}{l}\text { Hispanic } \\
\%(S E)\end{array}$ & $p$ \\
\hline Increase in goal directed activity & $93.93(0.82)$ & $95.06(0.83)$ & $90.56(2.26)$ & $90.07(3.77)$ & 0.131 \\
\hline Distractibility & $88.06(1.06)$ & $88.44(1.29)$ & $87.12(2.30)$ & $86.58(3.56)$ & 0.805 \\
\hline Flight of ideas/subjective experience that thoughts are racing & $79.94(1.37)$ & $81.26(1.57)$ & $75.15(3.12)$ & $76.47(3.59)$ & 0.123 \\
\hline More talkative than usual/pressure to talk & $72.40(1.55)$ & $72.27(1.83)$ & $76.33(3.05)$ & $68.96(3.55)$ & 0.291 \\
\hline Decreased need for sleep & $62.97(1.36)$ & $62.78(1.60)$ & $63.41(3.08)$ & $63.78(3.35)$ & 0.956 \\
\hline $\begin{array}{l}\text { Excessive involvement in pleasurable activities that have high } \\
\text { potential for painful consequences }\end{array}$ & $30.53(1.57)$ & $29.85(1.96)$ & $34.32(3.24)$ & $30.89(3.43)$ & 0.482 \\
\hline Inflated self-esteem or grandiosity & $28.70(1.55)$ & $25.34(1.71)^{\mathrm{a}, \mathrm{b}}$ & $39.87(3.32)^{\mathrm{a}}$ & $38.82(4.30)^{\mathrm{b}}$ & 0.001 \\
\hline
\end{tabular}

${ }^{\mathrm{a}, \mathrm{b}}$ Represent group differences based on pair-wise comparisons $(p<0.05)$.

Whites and African Americans exhibited nearly identical vitality scores (means $=48.5$ and 48.8 , respectively). In a multivariate linear regression model that controlled for sociodemographics and clinical characteristics, being white or African American was associated with significantly lower scores compared with Latinos (white, $b=-2.31, t=-2.37, p=0.206$; African American, $b=-2.47$, $t=-2.27, p=0.027$ ).

\section{Self-Report of Prior Schizophrenia Diagnosis}

Approximately $8.5 \%$ of persons with bipolar I disorder reported being told by a doctor they have schizophrenia $(95 \% \mathrm{CI}=$ $6.9 \%-10.5 \%)$. An overall difference was observed $\left(\chi^{2}[2]=7.44\right.$, $p=0.030)$ across the groups. The highest rate of self-reported diagnosis was African Americans (10.6\%), followed by whites $(8.7 \%)$ and then Latinos (5.0\%). In a multivariate logistic regression, controlling for sociodemographic and clinical characteristics, African Americans were significantly more likely to self-report a schizophrenia diagnosis compared with Latinos $(\mathrm{OR}=1.22,95 \% \mathrm{CI}=$ 1.02-1.47), but not whites.

\section{DISCUSSION}

The purpose of this study was to identify racial/ethnic differences in bipolar disorder. To our knowledge, this is the first study using nationally representative data from a community sample that compared racial/ethnic differences in the presentation of manic symptoms, the natural history of bipolar I disorder (i.e., age of onset, lifetime history and onset of depressive episodes, sociodemographic and clinical correlates), functional impairments, and self-reported diagnosis of schizophrenia or a psychotic disorder within a population-based (i.e., nontreatment seeking) sample. A unique aspect of this work was that DSM-IV symptoms were assessed using a structured clinical interview. This follows the recommendation of Patel et al. (2006) who called for research using blinded diagnostic and symptom assessment to remove clinician bias to help discern racial and ethnic differences (Patel et al., 2006). Overall, this study revealed few differences in bipolar I disorder across the racial/ethnic groups. The major symptom difference observed included differential rates of inflated self-esteem or grandiosity during mania, with African Americans and Latinos exhibiting 
rates approximately $50 \%$ higher than that of whites. Whites were also more likely to report a lifetime history of a depressive episode with an earlier age of onset. Overall, this study demonstrates that bipolar I disorder results in very similar presentations across racial and ethnic groups.

The differences observed in this study warrant further consideration, as they may be helpful in understanding errors in the diagnostic process. More specifically, the higher rates of reported self-esteem or grandiosity could be important when taking into account socioeconomic and cultural differences between the patient and clinician. African Americans and Latinos had significantly higher rates of this symptom compared with whites and were also significantly more likely to live in urban areas and have lower levels of education. These factors combined could lead to fundamentally different expressions in communicating symptoms. Another possibility is that African Americans and Latinos are interpreting this "inflated self-esteem or grandiosity" in a manner different than whites. Shrout et al. (2008) notes that language serves as a priming cue, which can make culture-linked mental health experiences more accessible, resulting in differential responses across racial and ethnic groups. The current study reported including interviews with only English-speaking subjects, so it remains unclear how language influenced the interpretation of the survey items, especially among subjects with English as a second language. Future research could explore in more detail the subjective experiences of mania using qualitative methods, similar to this type of research with depressive disorders (Kleinman, 2001, 2004; Lee et al., 2007).

Inflated self-esteem or grandiosity may be highly correlated with psychotic mania. This could not be examined in the present study as psychotic symptoms are not included in the AUDADIS-IV. Nonetheless, it is important to consider that prior research has found African American patients with bipolar disorder to present with increased frequency and severity of auditory hallucinations (Patel et al., 2006; Strakowski et al., 1996). A recent study by Strakowski et al. (2003) did not find any evidence that diagnostic differences in bipolar disorder could be attributed to symptoms, including mania, depression, psychosis, negative symptoms, and global psychopathology. However, this study did not examine differences in DSM-IV diagnostic criteria and the relationship to misdiagnosis. Future research should consider the extent to which this symptomand the manner in which it is expressed cross-culturally-may confound the diagnostic process.

Another significant difference in this study was that whites had higher rates of lifetime depressive episodes and were more likely to report an earlier onset of depression. Uelbelacker et al. (2008) found no apparent racial ethnic differences in the DSM-IV criteria for major depressive episodes based on the AUDADIS-IV. Whether a history of depressive episodes influences the accuracy of diagnosis remains unclear. It is possible that depressive episodes are an important cue for clinicians in diagnosing bipolar disorder, although BD can often be misdiagnosed as unipolar depression if the patient reports only depressive symptoms and no history of mania is assessed. When depressive episodes are not part of a clinical history, there may be greater risk of viewing manic symptoms, especially psychotic mania, as part of a schizophrenia spectrum disorder. Misdiagnosis of bipolar as unipolar depression remains an important problem (Matza et al., 2005), which leads to inappropriate care and increased service costs. At minimum, it is important that clinicians remain cognizant of this racial/ethnic difference. Additional research is needed to determine how the presence or absence of depression may confound the diagnostic process.

While African Americans and whites exhibited slightly greater levels of impairment as measured by the vitality scale of the SF-12, no other racial/ethnic differences were observed on any of the 9 other impairment measures. This finding was unexpected in light of the differences in socioeconomic status across the groups and their access to mental health services. At the same time, this finding is also consistent with Gonzalez et al. (2007) who found race and ethnic differences in 2000 patients enrolled in a treatment enhancement program for bipolar disorder, but no differences in overall functioning. This suggests that differences in functional impairments are unlikely to account for misdiagnosis, although it remains possible that clinicians may perceive certain racial and ethnic groups coming from lower socioeconomic backgrounds as being more impaired, increasing the likelihood of a schizophrenia diagnosis.

It is important to consider these findings in the context of the study limitations. Foremost, this study included English-speaking individuals within the US population. Compared with the reliability of other diagnoses, the AUDADIS-IV had a lower level of reliability for the diagnosis of mania. Other important clinical information such as duration of symptoms and course of illness were not available. The data are nationally representative but cannot be generalized to the clinical population of persons with bipolar I disorder. While no differences in rates of self-reported diagnosis of schizophrenia were observed, the reliability of this self-report is unknown.

Despite these limitations, this study helps show that bipolar disorder has more similarities than differences with respect to race and ethnicity. The results underscore the importance of developing more reliable clinical techniques for assessing bipolar disorder and increasing the utilization of such tools in routine care settings. Structured interview methods can be an important tool for addressing heterogeneity in this patient population, garnering history of episodes to more accurately diagnosis BD, facilitating accuracy of diagnosis, and matching patients with the best available treatment methods. Currently there are a limited number of practical tools that can be used to guide the diagnostic process. Service providers could also potentially benefit from guidelines that help guide the selection of the tools (Vega et al., 2007).

\section{REFERENCES}

Chen YR, Swann AC, Johnson BA (1998) Stability of diagnosis in bipolar disorder. J Nerv Ment Dis. 186:17-23.

Gonzalez JM, Thompson P, Escamilla M, Araga M, Singh V, Farrelly N, Thase ME, Miklowitz DJ, Bowden CL (2007) Treatment characteristics and illness burden among European Americans, African Americans and Latinos in the first 2,000 patients of the systematic treatment enhancement program for bipolar disorder. Psychopharmacol Bull. 40:31-46.

Grant BF, Dawson DA, Stinson FS, Chou PS, Kay W, Pickering R (2003) The Alcohol Use Disorder and Associated Disabilities Interview Schedule-IV (AUDADIS-IV): Reliability of alcohol consumption, tobacco use, family history of depression and psychiatric diagnostic modules in a general population sample. Drug Alcohol Depend. 71:7-16.

Grant BF, Hasin DS, Stinson FS, Dawson DA, Patricia Chou S, June Ruan W, Huang B (2005) Co-occurrence of 12-month mood and anxiety disorders and personality disorders in the US: Results from the national epidemiologic survey on alcohol and related conditions. J Psychiatr Res. 39:1-9.

Grant BF, Stinson FS, Dawson DA, Chou SP, Dufour MC, Compton W, Pickering RP, Kaplan K (2004) Prevalence and co-occurrence of substance use disorders and independent mood and anxiety disorders: Results from the Nationa Epidemiologic Survey on Alcohol and Related Conditions. Arch Gen Psychiatry. 61:807-816.

Hirschfeld RM, Lewis L, Vornik LA (2003) Perceptions and impact of bipolar disorder: How far have we really come? Results of the national depressive and manic-depressive association 2000 survey of individuals with bipolar disorder J Clin Psychiatry. 64:161-174.

Jones BE, Gray BA (1986) Problems in diagnosing schizophrenia and affective disorders among blacks. Hosp Community Psychiatry. 37:61-65.

Judd L, Akiskal HS (2003) The prevalence and disability of bipolar spectrum disorders in the US population: Re-analysis of the ECA database taking into account subthreshold cases. J Affective Disorders. 73:123-131.

Kennedy N, Boydell J, van Os J, Murray RM (2004) Ethnic differences in firs clinical presentation of bipolar disorder: Results from an epidemiological study. $J$ Affect Disord. 83:161-168. 
Kilbourne AM, Haas GL, Mulsant BH, Bauer MS, Pincus HA (2004) Concurrent psychiatric diagnoses by age and race among persons with bipolar disorder. Psychiatr Serv. 55:931-933.

Kirov G, Murray RM (1999) Ethnic differences in the presentation of bipolar affective disorder. Eur Psychiatry. 14:199-204.

Kleinman A (2001) Cross-cultural psychiatry: A psychiatric perspective on global change. Harv Rev Psychiatry. 9:46-47.

Kleinman A (2004) Culture and depression. N Engl J Med. 351:951-953.

Lawson WB, Hepler N, Holladay J, Cuffel B (1994) Race as a factor in inpatient and outpatient admissions and diagnosis. Hosp Community Psychiatry. 45:72-74.

Lee DT, Kleinman J, Kleinman A (2007) Rethinking depression: An ethnographic study of the experiences of depression among Chinese. Harv Rev Psychiatry. $15: 1-8$.

Matza LS, Rajagopalan KS, Thompson CL, de Lissovoy G (2005) Misdiagnosed patients with bipolar disorder: Comorbidities, treatment patterns and direct treatment costs. J Clin Psychiatry. 66:1432-1440.

Minsky S, Vega W, Miskimen T, Gara M, Escobar J (2003) Diagnostic patterns in Latino, African American and European American psychiatric patients. Arch Gen Psychiatry. 60:637-644.

Patel NC, Delbello MP, Strakowski SM (2006) Ethnic differences in symptom presentation of youths with bipolar disorder. Bipolar Disord. 8:95-99.

Perala J, Suvisaari J, Saarni SI, Kuoppasalmi K, Isometsa E, Pirkola S, Partonen T, Tuulio-Henriksson A, Hintikka J, Kieseppa T, Harkanen T, Koskinen S, Lonnqvist J (2007) Lifetime prevalence of psychotic and bipolar I disorders in a general population. Arch Gen Psychiatry. 64:19-28.

Raskin A, Crood TH, Herman KD (1975) Psychiatric history and symptom difference in black and white depressed inpatients. J Consult Clin Psychol. 43:73-80.

Shrout PE, Alegria M, Canino G, Guarnaccia PJ, Vega WA, Duan N, Cao Z (2008) Testing language effects in psychiatric epidemiology surveys with randomized experiments: Results from the National Latino and Asian American Study. Am J Epidemiol. 168:345-352.

Strakowski SM, Flaum M, Amador X, Bracha HS, Pandurangi AK, Robinson D, Tohen M (1996) Racial differences in the diagnosis of psychosis. Schizophr
Res. 21:117-124.

Strakowski SM, Keck PE Jr, Arnold LM, Collins J, Wilson RM, Fleck DE, Corey $\mathrm{KB}$, Amicone J, Adebimpe VR (2003) Ethnicity and diagnosis in patients with affective disorders. J Clin Psychiatry. 64:747-754.

Strakowski SM, Lonczak HS, Sax KW, West SA, Crist A, Mehta R, Thienhaus OJ (1995) The effects of race on diagnosis and disposition from a psychiatric emergency service. J Clin Psychiatry. 56:101-107.

Trivedi MH, Rush AJ, Crismon ML, Kashner TM, Toprac MG, Carmody TJ, Key T, Biggs MM, Shores-Wilson K, Witte B, Suppes T, Miller AL, Altshuler KZ, Shon SP (2004a) Clinical results for patients with major depressive disorder in the Texas Medication Algorithm Project. Arch Gen Psychiatry. 61:669-680.

Trivedi MH, Rush AJ, Ibrahim HM, Carmody TJ, Biggs MM, Suppes T, Crismon ML, Shores-Wilson K, Toprac MG, Dennehy EB, Witte B, Kashner TM (2004b) The Inventory of Depressive Symptomatology, Clinician Rating (IDS-C) and Self-Report (IDS-SR) and the Quick Inventory of Depressive Symptomatology, Clinician Rating (QIDS-C) and Self-Report (QIDS-SR) in public sector patients with mood disorders: A psychometric evaluation. Psychol Med. 34:73-82.

Uebelacker LA, Strong D, Weinstock LM, Miller IW (2008) Use of item response theory to understand differential functioning of DSM-IV major depression symptoms by race, ethnicity and gender. Psychol Med. 39:591-601.

van Os J, Takei N, Castle DJ, Wessely S, Der G, MacDonald AM, Murray RM (1996) The incidence of mania: Time trends in relation to gender and ethnicity. Soc Psychiatry Psychiatr Epidemiol. 31:129-136.

Vega WA, Karno M, Alegria M, Alvidrez J, Bernal G, Escamilla M, Escobar J, Guarnaccia P, Jenkins J, Kopelowicz A, Lagomasino IT, Lewis-Fernandez R, Marin H, Lopez S, Loue S (2007) Research issues for improving treatment of U.S. Hispanics with persistent mental disorders. Psychiatr Serv. 58:385-394.

Vojta C, Kinosian B, Glick H, Altshuler L, Bauer MS (2001) Self-reported quality of life across mood states in bipolar disorder. Compr Psychiatry. 42:190-195.

Ware J Jr, Kosinski M, Keller SD (1996) A 12-Item Short-Form Health Survey: Construction of scales and preliminary tests of reliability and validity. Med Care. 34:220-233.

Zhang AY, Snowden LR (1999) Ethnic characteristics of mental disorders in five U.S. communities. Cultur Divers Ethnic Minor Psychol. 5:134-146. . 